\title{
ARTICLE
}

Cite this: DOI: $10.1039 / \times 0 \times x 00000 x$

\section{Synthesis and post-polymerization reaction of end- clickable stereoregular polymethacrylates via termination of stereospecific living anionic polymerization}

Received 00th January 2012, Accepted 00th January 2012

DOI: $10.1039 / \times 0 \times x 00000 x$

www.rsc.org/

\author{
Yasuhiro Kohsaka, Takashi Kurata, Kazuki Yamamoto, Shoya Ishihara, and \\ Tatsuki Kitayama*
}

\begin{abstract}
Poly(methyl methacrylate)s with high stereoregularity and clickable end-groups were synthesized via terminating reactions with $\alpha$-(halomethyl)acrylates in stereospecific living anionic polymerization. The terminating reaction was so efficient and tolerant to the reaction conditions that almost quantitative end-functionalization was achieved in isotactic- and syndiotactic-specific polymerization systems. The terminating reactions were also achieved in the polymerizations of vinyl methacrylate and trimethylsilyl methacrylate. For the polymerization of butyl acrylate, however, the termination efficiency was limited as high as $69 \%$. Further quantitative end-functionalization of the incorporated $\mathrm{C}=\mathrm{C}$ double bond at $\omega$-end was achieved with various thiols catalyzed by $\mathrm{Et}_{3} \mathrm{~N}$. The base-catalysed thiol-ene reaction of the stereoregular poly(vinyl methacrylate) with $\omega$-end $\mathrm{C}=\mathrm{C}$ double bond proceeded selectively to retain vinyl ester functions, and the subsequent hydrolysis afforded $\omega$-functional stereoregular poly(methacrylic acid). A combination of the terminating agent with a protected lithium amide afforded stereoregular poly(methyl methacrylates) with orthogonally clickable $\alpha$ - and $\omega$-ends.
\end{abstract}

\section{Introduction}

End-functional polymers ${ }^{1}$ have important roles not only in the synthesis of block copolymer ${ }^{2}$ and branched copolymer ${ }^{3-5}$ but also in various application areas such as attachment of macromolecules onto material surfaces ${ }^{6,7}$ and construction of bio/artificial hybrid materials. ${ }^{8-10}$ In particular, since the facile and quantitative reaction systems based on the concept of 'click chemistry' have been established, polymers with clickable endfunctionalities have attracted polymer chemists and material scientists. ${ }^{11,12}$ Clickable end-functionalities are generally introduced by living polymerizations with an initiator and/or a terminating agent bearing clickable functional groups or their precursors. For example, reversible addition fragmentation transfer (RAFT) polymerization gives a dithioester group in $\omega$ end, which can be converted to thiol by a treatment with primary amine and then conducted to thiol-ene or thiol-yne click chemistry. ${ }^{12-15}$ Recently, Perrier et al. have reported a new chain transfer agent with carbonyl azide group, which affords the incorporation of an isocyanate group for click chemistry into $\alpha$-end. ${ }^{16}$ Another way from living polymerization to click chemistry is atom transfer radical polymerization (ATRP) and the following copper-catalyzed azide-alkyne cycloaddition (CuAAC) using azide group at $\omega$-end derived from terminal halogen atoms. In fact, Matyjaszewski et al. have succeeded in the direct combination of ATRP and CuAAC reaction in onepot system. ${ }^{17-19}$ Moreover, the conversions of bromo atom at $\omega$ end to cyclopentadienyl group for Diels-Alder click reaction ${ }^{20}$ and to thiol group for thiol-ene and thiol-yne click reaction ${ }^{21}$ are also possible. There are many reports on the ATRP initiators with clickable group, some of which are now commercially available. , $2,22,23$

Besides end-functionality, control of stereoregularity has also been a major target of precise polymerization chemistry, ${ }^{24}$ because stereoregularity often affects polymer properties. For instance, isotactic poly(methyl methacrylate) (it-PMMA) have a glass transition temperature $\left(T_{\mathrm{g}}\right)$ around $50{ }^{\circ} \mathrm{C}$, while syndiotactic (st-)PMMA exhibits $T_{\mathrm{g}}$ at $120{ }^{\circ} \mathrm{C} .{ }^{25}$ Therefore, numerous efforts have been paid for the control of stereoregularity of PMMA. In radical polymerization, highly 
isotactic PMMAs ( $\mathrm{mm}$ content > 99.9\%) was synthesized via the polymerization of bulky monomers such as 1-phenylsuberyl methacrylate and the post-polymerization modification for isotactic polymer, ${ }^{26-28}$ and polymerization of MMA in fluoroalkyl alcohols for syndiotactic polymer $(r r$ content $=$ 93\%). ${ }^{29,30}$ Furthermore, the simultaneous control of stereoregularity and molecular weight has been achieved by living radical polymerization at low temperature $\left(\sim-78{ }^{\circ} \mathrm{C}\right)$ in fluorous alcohols, where $s t$-PMMA ( $r r$ content $\sim 85 \%$ ) could be synthesized. ${ }^{31}$ More sophisticated control of stereoregularity and molecular weight could be achieved by stereospecific anionic polymerizations, which afford stereoregular PMMAs with high tacticity $\left(m m\right.$ content $\sim 99.5 \%$ for $i t-\mathrm{PMMA}^{32}$ and $r r$ content $=96 \%$ for $s t$-PMMA ${ }^{33}$ ) with narrow molecular weight distribution. In these stereospecific anionic polymerization systems, non-polar solvents such as toluene are used to facilitate interaction of the living polymer anion to counter cation or some additives, achieving the stereoregulation. As a consequence, the reactivities of the living anions are suppressed so low that they can scarcely react with typical terminating agents such as allyl ${ }^{34}$ and benzyl ${ }^{35}$ halides, generally used for anionic polymerization in polar solvents. Thus, multidentate or strong amine ligands are required to activate the living anions for the end-functionalization by terminating agents. ${ }^{36}$ For a functional initiator approach, the reagent design should comply with the demand of proper reactivity to allow the simultaneous control of molecular weight and stereoregularity as well as of tolerance to their functional groups. In fact, there are only a few reports of functional initiator for stereospecific anionic polymerization of MMA. ${ }^{37,38}$

Recently, we have found that $\alpha$-(halomethyl)acrylates (1) are effective terminating agents for stereoregular PMMA living anions, where $\mathbf{1}$ undergoes addition-fragmentation reactions $\left(\mathrm{S}_{\mathrm{N}} 2\right.$ ' reaction) with nucleophiles (living PMMA anions) to give the polymers with $\omega$-end functionality of $\alpha, \beta$-unsaturated ester. ${ }^{39}$ The resulting polymers are susceptible to further chemical modification via Michael addition click chemistry. In this article, we report the details and advanced results of the termination and the subsequent end-functionalization.

\section{Experiment}

\section{Materials}

$\mathrm{CH}_{2} \mathrm{Cl}_{2}$ (Wako, super dehydrated grade) was dried over $\mathrm{CaH}_{2}$ (Nacalai Tesque) and distilled under high vacuum just before use. Toluene (Aldrich, anhydrous grade) was dehydrated with red colored complex of butyllithium ( $n$-BuLi, $1.64 \mathrm{M}$ hexane solution, Kanto Chemical) and 1,1-diphenylethylene (Acros Organics), and distilled under high vacuum just before use. Ethylaluminum bis(2,6-di-t-butylphenoxide) [EtAl(ODBP) and methylaluminum bis(2,6-di-t-butylphenoxide) $\left[\mathrm{MeAl}(\mathrm{ODBP})_{2}\right]$ were prepared according to our previous report $^{40}$ and stored as toluene solutions under nitrogen atmosphere. MMA (Nacalai Tesque), vinyl methacrylate (VMA, Tokyo Chemical Industry), and butyl acrylate (BA, Tokyo
Chemical Industry) were fractionally distilled and stored over $\mathrm{CaH}_{2}$. The monomers were distilled over $\mathrm{CaH}_{2}$ under high vacuum just before use. $\mathrm{Me}_{3} \mathrm{SiOLi}$ (Aldrich) was dried in vacuo at $100{ }^{\circ} \mathrm{C}$ for several hours and used as dry toluene or $\mathrm{CH}_{2} \mathrm{Cl}_{2}$ solution. The received reagent contains a significant amount of insoluble material, and thus the supernatant solution was used for polymerization. Isopropyl $\alpha$-lithioisobutyrate (Li-iPrIB) was prepared and recrystallized in toluene according to our previous report. ${ }^{32}$ Ethyl $\alpha$-(chloromethyl)acrylate (1a) and ethyl $\alpha$ (bromomethyl)acrylate (1b) were synthesized from ethyl $\alpha$ (hydroxymethyl)acrylate, a kind gift from Nippon Shokubai Co., Ltd, according to our previous report. ${ }^{39}$ 1a (bp 44.3$45.0{ }^{\circ} \mathrm{C} / 2.5 \mathrm{mmHg}$ ) and $\mathbf{1 b}$ (bp 45.0-45.3 ${ }^{\circ} \mathrm{C} / 2.0 \mathrm{mmHg}$ ) were distilled under reduced pressure and stored under nitrogen atmosphere in the presence of Molecular Sieves 4A (MS4A, Nacalai Tesque) at $-20 \quad{ }^{\circ} \mathrm{C}$. Ethyl 2-methylpent-4-enoate (Aldrich) and diisopropylamine were dried over $\mathrm{CaH}_{2}$, distilled under high vacuum, and stored as toluene solutions. Benzylidene-bis(tricyclohexylphosphine)dichlororuthenium (first generation Grubbs' catalyst, Aldrich) and other reagents were used as purchased without further purification.

\section{Instruments}

${ }^{1} \mathrm{H}$ and ${ }^{13} \mathrm{C}$ NMR spectra were measured in $\mathrm{CDCl}_{3}$ (Aldrich) on a Unity Inova 500 spectrometer (Varian) and an ECS-400 spectrometer (JEOL). Chemical shifts in ${ }^{1} \mathrm{H}$ NMR spectra were referred to the signal of tetramethylsilane (TMS). Molecular weights and its distributions of the polymers were determined at $40{ }^{\circ} \mathrm{C}$ by size-exclusion chromatography (SEC) using a GPC-900 chromatograph (JASCO) equipped with two SEC columns [Polymer Laboratories, PL-gel, Mixed C $(300 \mathrm{~mm}$ $\times 7.5 \mathrm{~mm}$ )], using tetrahydrofuran (THF) as an eluent at a flow rate of $0.8 \mathrm{~mL} \cdot \mathrm{mL}^{-1}$, and calibrated against standard PMMA samples (Shodex, MW: $1.25 \times 10^{6}, 6.59 \times 10^{5}, \quad 1.95 \times 10^{5}$, $\left.4.96 \times 10^{4}, 2.06 \times 10^{4}, 6.82 \times 10^{3}, 2.00 \times 10^{3}\right)$.

\section{Trimethylsilyl Methacrylate (TMSMA)}

Under nitrogen atmosphere, chlorotrimethylsilane $(100 \mathrm{~mL}$, $0.790 \mathrm{mmol}$ ) was added dropwise to a suspension of potassium methacrylate $(99.3 \mathrm{~g}, 0.800 \mathrm{mmol})$ in $\mathrm{Et}_{2} \mathrm{O}(750 \mathrm{~mL})$ containing MS4A (15 g). After $21 \mathrm{~h}$, the precipitate was removed by filtration over Cerite ${ }^{\circledR}$ No. 535 (Wako), and the filtrate was concentrated. The residue was distilled twice under reduced pressure with Vigreux column $\left(40.5{ }^{\circ} \mathrm{C} / 16 \mathrm{mmHg}\right)$ to give TMSMA as colorless oil (70.7 g). Yield: $55.8 \%$. Purity: $99.6 \%$. $d=0.8898 \mathrm{~g} / \mathrm{cm}^{3} .{ }^{1} \mathrm{H}$ NMR $\left(400 \mathrm{MHz}, \mathrm{CDCl}_{3}, 30{ }^{\circ} \mathrm{C}\right) \delta 6.09$ $\left(\mathrm{dd}, J_{1}=1.8 \mathrm{~Hz}, J_{2}=0.9 \mathrm{~Hz}, 1 \mathrm{H}, \mathrm{C} H \mathrm{H}=\right), 5.58\left(\mathrm{dd}, J_{1}=1.8 \mathrm{~Hz}\right.$, $\left.J_{2}=1.6 \mathrm{~Hz}, 1 \mathrm{H}, \mathrm{CH} H=\right), 1.91\left(\mathrm{dd}, J_{1}=1.6 \mathrm{~Hz}, J_{2}=0.9 \mathrm{~Hz}, 3 \mathrm{H}\right.$, $\left.\alpha-\mathrm{CH}_{3}\right), 0.31$ (s, 9H, $\mathrm{SiMe}_{3}$ ) ppm. ${ }^{13} \mathrm{C} \mathrm{NMR}\left(100 \mathrm{MHz}, \mathrm{CDCl}_{3}\right.$, $\left.30{ }^{\circ} \mathrm{C}\right) \delta 168.4(\mathrm{C}=\mathrm{O}), 138.3(\alpha), 126.6(\beta), 18.9\left(\mathrm{OCH}_{3}\right), 0.44$ $\left(\mathrm{SiMe}_{3}\right) \mathrm{ppm}$.

\section{Polymerization}

All the polymerization reactions were carried out under dried nitrogen atmosphere in glass ampoules fitted with three-way stopcocks and the solvents and reagents were transferred via 
hypodermic syringes. A typical procedure (Table 1, Run 2): To a glass ampoule filled in dried nitrogen passed through MS4A at $-78{ }^{\circ} \mathrm{C}, \mathrm{CH}_{2} \mathrm{Cl}_{2}(5.0 \mathrm{~mL}), \mathrm{Me}_{3} \mathrm{SiOLi}(2.5 \mathrm{mmol})$, and $\mathrm{Li}-$ $i$ PrIB $(0.25 \mathrm{mmol})$ were added at room temperature. The reaction mixture was cooled to $-78{ }^{\circ} \mathrm{C}$, and the polymerization was started by the addition of MMA (5.0 mmol). After $1 \mathrm{~h}, \mathbf{1 a}$ (1.25 mmol) was added to the polymerization mixture and reacted for further $1 \mathrm{~h}$. Then the reaction was finally quenched by $\mathrm{HCl}$ aq- $\mathrm{MeOH}$ solution, and the polymer was recovered by precipitation with hexane, filtered and washed with hexane, acidic water and water, successively, and dried in vacuo at 40 ${ }^{\circ} \mathrm{C}$.

\section{Thiol-ene 'click' reaction}

A typical procedure: To a solution of $s t$-PMMA (st-2, $64 \mathrm{mg}$, $20 \mu \mathrm{mol}$ of the functional group) in $\mathrm{CH}_{3} \mathrm{CN}(0.20 \mathrm{~mL})$ was added a catalytic amount of $\left(\mathrm{Et}_{3} \mathrm{~N}\right)$ and $\mathbf{2 b}(0.17 \mathrm{~mL}, 2.0 \mathrm{mmol})$. The reaction mixture was stirred at ambient temperature for 12 $\mathrm{h}$ and poured into hexane $(30 \mathrm{~mL})$. The precipitate was collected by centrifugation and washed with water, then dried in vacuo for $6 \mathrm{~h}$ to give the corresponding polymer $(62 \mathrm{mg})$. For the PMMA with higher molar masses (it-4, st-5, and st-6), the volume of the solvent was $0.50 \mathrm{~mL}$ and the molar concentration of the functional group was $20 \mathrm{mM}$ instead of $100 \mathrm{mM}$ in the typical case described above.

\section{$\omega$-Functional stereoregular poly(methacrylic acid)}

To a solution of it-poly(VMA) (V1, $74 \mathrm{mg}, 10 \mu \mathrm{mol})$ in $\mathrm{Et}_{3} \mathrm{~N}$ $(0.209 \mathrm{~mL}, 1.50 \mathrm{mmol})$ was added 2-mercaptoethylammonium chloride (2d, $0.113 \mathrm{~g}, 1.00 \mathrm{mmol})$. After $12 \mathrm{~h}, \mathrm{H}_{2} \mathrm{O}(30 \mathrm{~mL})$ was added, and the product was extracted with $\mathrm{CHCl}_{3}(30 \mathrm{~mL})$. The organic layer was concentrated, and the residue was dried in vacuo. The obtained $\omega$-functional polymer $(70 \mathrm{mg}, 0.63$ $\mathrm{mmol} /$ unit) was dissolved in $\mathrm{CF}_{3} \mathrm{COOH}(1.0 \mathrm{~mL}, 13 \mathrm{mmol})$ and $\mathrm{H}_{2} \mathrm{O}(0.23 \mathrm{~mL}, 13 \mathrm{mmol})$. The reaction mixture was heated at $70{ }^{\circ} \mathrm{C}$ for $3 \mathrm{~h}$ and poured into acetone $(30 \mathrm{~mL})$. The precipitate was collected by centrifugation and dried in vacuo to give a poly(methacrylic acid) $(57 \mathrm{mg})$.

\section{Amine-isocyanate 'click' reactions}

st-PMMA (st-13) was reacted with 11-mercaptoundec-1-ene (2g) in a similar manner as described above. The product (40 $\mathrm{mg}, 12 \mu \mathrm{mol})$ was dissolved in $\mathrm{CDCl}_{3}(0.60 \mathrm{~mL})$ and $\mathrm{Et}_{3} \mathrm{~N}(18$ $\mu \mathrm{L}, 120 \mu \mathrm{mol})$. 2-isocyanatoethyl methacrylate $(\mathbf{4 a}, 17 \mu \mathrm{L}, 120$ $\mu \mathrm{mol})$ was added, and the reaction was monitored by ${ }^{1} \mathrm{H}$ NMR spectroscopy. After $15 \mathrm{~h}$, the reaction mixture was poured into hexane $(50 \mathrm{~mL})$. The precipitate was collected by centrifugation, dissolved in $\mathrm{CHCl}_{3}(10 \mathrm{~mL})$, washed with $1 \mathrm{M}$ $\mathrm{HCl}$ aq $(10 \mathrm{~mL})$ and $\mathrm{H}_{2} \mathrm{O}(10 \mathrm{~mL})$, and concentrated. The residue was dried in vacuo to give a polymeric product $(40 \mathrm{mg})$.

\section{Thiol-ene and amine-isocyanate 'double click' reactions}

$S$-(Undec-10-en-1-yl) acetothioate $(0.25 \mathrm{~mL}, 1.0 \mathrm{mmol})$ was treated with propylamine $(0.16 \mathrm{~mL}, 2.0 \mathrm{mmol})$ in $\mathrm{CH}_{3} \mathrm{CN}(0.20$ $\mathrm{mL}$ ) at ambient temperature for $3 \mathrm{~h}$, and st-PMMA (st-14, 64 $\mathrm{mg}, 20 \mu \mathrm{mol})$ was added. After $14 \mathrm{~h}$, phenyl isocyanate (4b, $0.33 \mathrm{~mL}, 3.0 \mathrm{mmol}$ ) was added. After $12 \mathrm{~h}$, the reaction mixture was diluted with $\mathrm{CHCl}_{3}(1 \mathrm{~mL})$ and poured into hexane (50 $\mathrm{mL}$ ). The precipitate was collected by centrifugation, washed with hexane, and dried in vacuo. The precipitate was dissolved in $\mathrm{CHCl}_{3}(1 \mathrm{~mL})$, and insoluble product was removed by filtration. The solution was concentrated, and the residue was dissolved in acetone. The solution was poured into water (15 $\mathrm{mL})-\mathrm{MeOH}(35 \mathrm{~mL})$ cosolvent, and the precipitate was collected by centrifugation and dried in vacuo at $40{ }^{\circ} \mathrm{C}$ to give a polymeric product $(16 \mathrm{mg})$.

\section{Synthesis of telechelic it-PMMA (it-7m)}

All reagents were added via hypodermic syringes. To a glass ample filled in dried nitrogen gas passed through MS4A at $78{ }^{\circ} \mathrm{C}$, to a solution of $n$-BuLi in hexane $(1.64 \mathrm{M}, 0.24 \mathrm{~mL}$, $0.40 \mathrm{mmol})$ was added diisopropylamine in toluene $(0.98 \mathrm{M}$, $0.24 \mathrm{~mL}, 0.46 \mathrm{mmol}$ ) was added dropwise. After $1 \mathrm{~h}$, ethyl 2methylpent-4-enoate in toluene $(0.75 \mathrm{M}, 0.53 \mathrm{~mL}, 0.40 \mathrm{mmol})$ was added to the viscous reaction mixture cooled over water bath. After $1 \mathrm{~h}, \mathrm{Me}_{3} \mathrm{SiOLi}$ in toluene $(0.99 \mathrm{M}, 2.0 \mathrm{~mL}, 2.0$ $\mathrm{mmol})$ and toluene $(2.0 \mathrm{~mL})$ was added, and the reaction mixture was cooled at $-78{ }^{\circ} \mathrm{C}$. MMA $(1.1 \mathrm{~mL}, 10 \mathrm{mmol})$ was added to initiate the polymerization. After $30 \mathrm{~min}$, the reaction mixture was warmed at $-30{ }^{\circ} \mathrm{C}$, and $\mathbf{1 a}(1.3 \mathrm{~mL}, 1.0 \mathrm{mmol})$ was added. The reaction was finally quenched by $5 \mathrm{M} \mathrm{HCl}$ aq $(0.7$ $\mathrm{mL})$. The reaction mixture was then poured into hexane (150 $\mathrm{mL}$ ), and the precipitate was collected by centrifugation and dried in vacuo to afford the product (1.36 g). It was dissolved in

Table 1. Terminating reaction with $\alpha$-(halomethyl)acrylates in isotactic-specific anionic polymerization of MMA. ${ }^{a}$

\begin{tabular}{|c|c|c|c|c|c|c|c|c|c|c|c|c|c|}
\hline \multirow[b]{2}{*}{ Run } & \multicolumn{2}{|c|}{ Polymerization } & \multicolumn{4}{|c|}{ Termination } & \multirow[b]{2}{*}{ Polymer } & \multirow[b]{2}{*}{$M_{\mathrm{n}}{ }^{d}$} & \multirow[b]{2}{*}{$M_{\mathrm{w}} / M_{\mathrm{n}}{ }^{d}$} & \multicolumn{4}{|c|}{ Tacticity $/ \%$} \\
\hline & $\begin{array}{c}{[\mathrm{MMA}]_{0} /} \\
{[\mathrm{Li}-i \mathrm{PrIB}]_{0}}\end{array}$ & Solvent & $T^{\mathrm{b}}$ & Equiv. ${ }^{c}$ & Temp. $/{ }^{\circ} \mathrm{C}$ & Time/ h & & & & $\mathrm{mm}$ & $m r$ & $r r$ & $F^{f} / \%$ \\
\hline 1 & $20 / 1$ & $\mathrm{CH}_{2} \mathrm{Cl}_{2}$ & $\mathrm{H}_{3} \mathrm{O}^{+}$ & excess & -78 & $>0$ & it-1 & 8000 & 1.22 & 98 & 2 & $\sim 0$ & - \\
\hline 2 & $20 / 1$ & $\mathrm{CH}_{2} \mathrm{Cl}_{2}$ & $1 a$ & 5.0 & -78 & 1 & it-2 & 7000 & 1.18 & & & & 90 \\
\hline 3 & $20 / 1$ & $\mathrm{CH}_{2} \mathrm{Cl}_{2}$ & 1a & 5.0 & -40 & 1 & it-3 & 6800 & 1.19 & & & & 93 \\
\hline 4 & $100 / 1$ & $\mathrm{CH}_{2} \mathrm{Cl}_{2}$ & $1 \mathbf{a}$ & 5.0 & -78 & 1 & it-4 & 28000 & 1.32 & 97 & 3 & $\sim 0$ & 93 \\
\hline 5 & $20 / 1$ & $\mathrm{CH}_{2} \mathrm{Cl}_{2}$ & $1 \mathbf{b}$ & 5.0 & -78 & 1 & it-5 & 8000 & 1.20 & & & & 93 \\
\hline 6 & $20 / 1$ & Toluene & $1 b$ & 5.0 & $-78 \rightarrow 0^{\mathrm{g}}$ & 1 & it-6 & 7500 & 1.26 & & & & 96 \\
\hline
\end{tabular}

${ }^{a}$ Polymerizations of MMA $(5.0 \mathrm{mmol})$ were carried out in solvent $(5.0 \mathrm{~mL})$ at $-78{ }^{\circ} \mathrm{C}$ for $1 \mathrm{~h} .\left[\mathrm{Me}_{3} \mathrm{SiOLi}\right]_{0} /[\mathrm{Li}-i \mathrm{PrIB}]_{0}=10 / 1 .{ }^{b} \mathrm{Terminating}$ agent.

${ }^{c}$ Equivalent of terminating agent to Li-iPrIB. ${ }^{d}$ Determined by SEC (PMMA standards). ${ }^{e}$ Estimated by ${ }^{1} \mathrm{H}$ NMR spectra. ${ }^{f}$ End-functionalization efficiency

${ }^{g}$ Terminating agent was added at $-78{ }^{\circ} \mathrm{C}$ and then the reaction system was warmed to $0{ }^{\circ} \mathrm{C}$. 


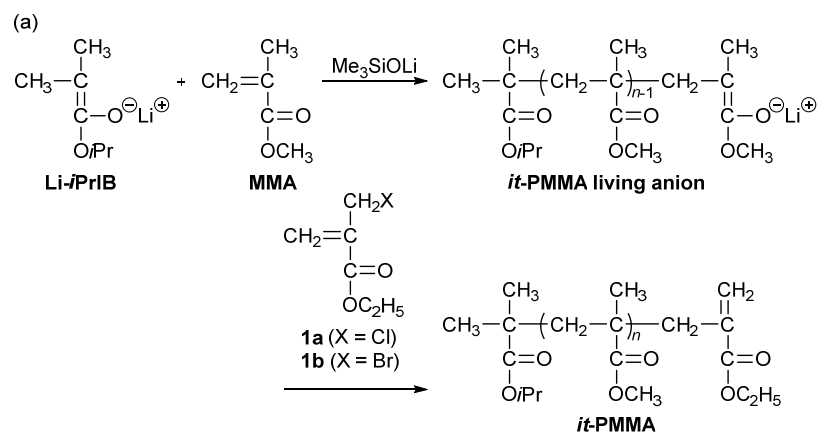

(b)

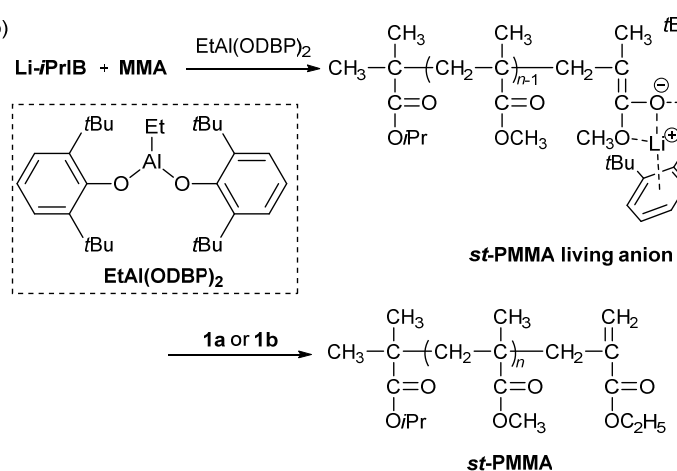

Scheme 1. Termination of (a) it- or (b) st-PMMA living anions with 1

$\mathrm{CHCl}_{3}$ and washed with $1 \mathrm{M} \mathrm{HCl} \mathrm{aq}(20 \mathrm{~mL})$ twice and $\mathrm{H}_{2} \mathrm{O}$ $(20 \mathrm{~mL})$. The organic layer was concentrated and dried in vacuo to recover the product (it-7, $0.83 \mathrm{~g}$ ). The obtained itPMMA (it-7m) was reacted with $\mathbf{2 g}$ in a similar manner described above to give a telechelic it-PMMA.

\section{Attempt of cyclization telechelic it-PMMA by olefin-metathesis reaction}

The telechelic it-PMMA obtained above $(57 \mathrm{mg}, 10 \mu \mathrm{mol})$ was dissolved in anhydrous $\mathrm{CH}_{2} \mathrm{Cl}_{2}(100 \mathrm{~mL})$ distilled over $\mathrm{CaH}_{2}$ under vacuum. First generation Grubbs' catalyst (19 mg, 20 $\mu \mathrm{mol}$ ) was added to the solution, and the reaction mixture was refluxed for 5 days, passed through activated alumina layer, and concentrated to give the product $(37 \mathrm{mg})$.

\section{Results and Discussion}

\section{Terminating reaction of $i t$-PMMA living anion}

According to the previous report, ${ }^{32}$ isotactic-specific living polymerization of MMA was carried out in $\mathrm{CH}_{2} \mathrm{Cl}_{2}$ at $-78{ }^{\circ} \mathrm{C}$ with $\mathrm{Li}-i \mathrm{PrIB} / \mathrm{Me}_{3} \mathrm{SiOLi}$ (Scheme 1a). After $1 \mathrm{~h}$, the conversion of MMA reached $100 \%$, and terminating agents, $\mathrm{HCl}$ aq- $\mathrm{MeOH}$ solution (Table 1, Run 1) or 1a (Run 2) were added. Fig. 1 shows the ${ }^{1} \mathrm{H}$ NMR spectra of the resulting polymers, it-1 and it-2. In both cases, the isotacticity $(\mathrm{mm}$ contents), determined from the integral ratio of $\alpha-\mathrm{CH}_{3}$ signals were higher than $98 \%$. In the ${ }^{1} \mathrm{H}$ NMR spectrum of it-1 (Fig. 1a), the signal assignable to $\mathrm{CH}$ proton at $\omega$-end was observed around $2.44 \mathrm{ppm}$. In contrast, the $\omega-\mathrm{CH}$ signal was very weak in the ${ }^{1} \mathrm{H}$ NMR spectrum of it-2, while the signals assignable to vinylidene (6.17 and $5.48 \mathrm{ppm}), O$-methylene (4.17 ppm), and allylic (2.62 and $2.47 \mathrm{ppm}$ ) protons were observed (Fig. 1b), which clearly indicate the presence of an $\alpha, \beta$-unsaturated ethyl ester unit, supporting effective terminating reaction with 1a to afford it-PMMA with $\omega$-end $\mathrm{C}=\mathrm{C}$ bond. The endfunctionalization ratio $(F)$ was determined as $90 \%$ from the intensity ratio of the vinylidene signals at $\omega$-end to the $\mathrm{CH}$ signal of isopropyl ester at $\alpha$-end. Termination at higher temperature $\left(-40{ }^{\circ} \mathrm{C}\right)$ did not significantly improve the endfunctionalization ratio ( $F=93 \%$, Run 3$)$. The terminating reaction was proved effective for an it-PMMA anion with higher molecular weight (Run 4: $M_{\mathrm{n}}=28000, M_{\mathrm{w}} / M_{\mathrm{n}}=1.32, F$ $=93 \%)$. The bromide $1 \mathbf{b}$ also gave a similar result (Run 5: $F=$ $93 \%$ ), indicating the leaving ability of halogen atom is not significant in the terminating reaction. In contrast to the polymerization in $\mathrm{CH}_{2} \mathrm{Cl}_{2}$, the polymerization in toluene at $-78{ }^{\circ} \mathrm{C}$ resulted in gelation of the reaction mixture. Thus, the reaction mixtures were gradually heated up to $0{ }^{\circ} \mathrm{C}$ after the addition of the terminating agents at $-78{ }^{\circ} \mathrm{C}$ in order to mix them homogeneously. Though the living it-PMMA anion may undergo spontaneous chain-end cyclization termination at $0{ }^{\circ} \mathrm{C}$, the end-functionalization ratio was even higher (Run 6: $F=$ $96 \%$ ). Consequently, the efficiency of terminating reaction is not significantly dependent on the reaction conditions.

\section{Terminating reaction of st-PMMA living anion}

In a similar way, syndiotactic specific living polymerization of MMA was carried out in $\mathrm{CH}_{2} \mathrm{Cl}_{2}$ at $-78{ }^{\circ} \mathrm{C}$ with a binary initiator, $\mathrm{Li}-i \mathrm{PrIB} / \mathrm{EtAl}(\mathrm{ODBP})_{2}$ for $24 \mathrm{~h}$ (Conv. 100\%) and terminated with $\mathrm{HCl}$ aq- $\mathrm{MeOH}$ solution (Table 2, Run 7) or 1a (Run 8) to give the corresponding polymers, st-1 and st-2, respectively (Scheme 1b). Fig. 2 shows the ${ }^{1} \mathrm{H}$ NMR spectra of st-1 and st-2. In both cases, syndiotacticity determined from the

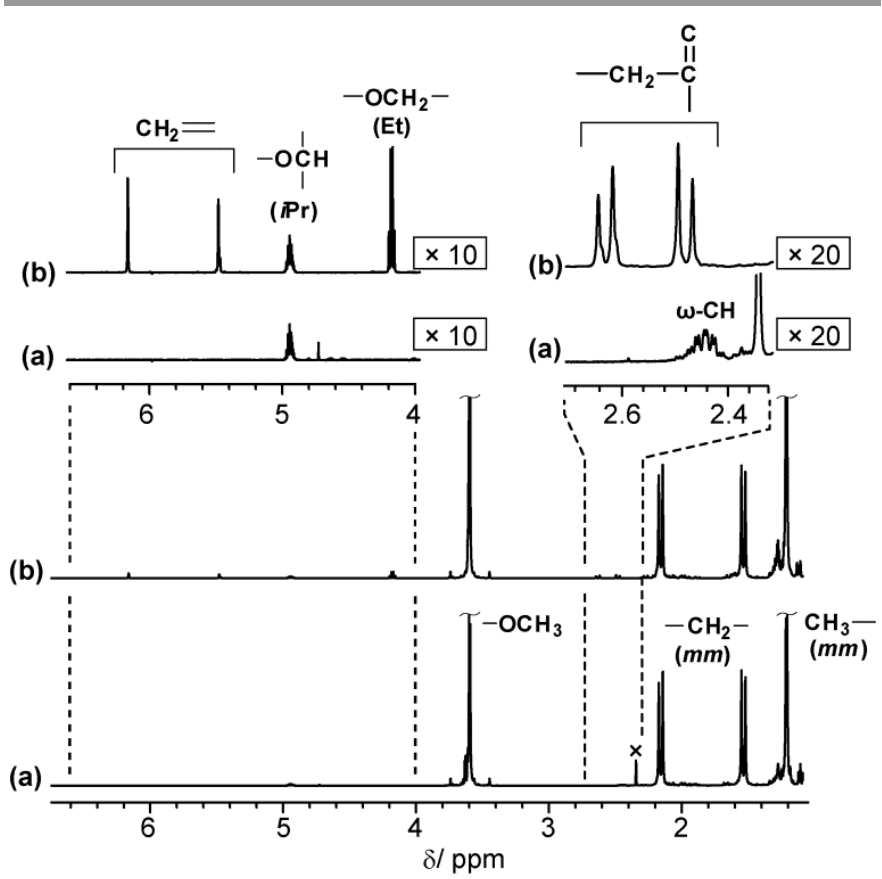

Fig.1 ${ }^{1} \mathrm{H}$ NMR spectra of (a) it-1 and (b) it-2 $\left(500 \mathrm{MHz}, \mathrm{CDCl}_{3}, 55^{\circ} \mathrm{C}\right) . \times$ : toluene. 
Table 2. Terminating reaction with $\alpha$-(halomethyl)acrylates in syndiotactic-specific anionic polymerization of MMA. ${ }^{a}$

\begin{tabular}{|c|c|c|c|c|c|c|c|c|c|c|c|c|c|}
\hline \multirow[b]{2}{*}{ Run } & \multicolumn{2}{|c|}{ Polymerization } & \multicolumn{4}{|c|}{ Termination } & \multirow[b]{2}{*}{ Polymer } & \multirow[b]{2}{*}{$M_{\mathrm{n}}{ }^{d}$} & \multirow[b]{2}{*}{$M_{\mathrm{w}} / M_{\mathrm{n}}{ }^{d}$} & \multicolumn{4}{|c|}{ Tacticity $1 \%$} \\
\hline & $\begin{array}{c}{[\mathrm{MMA}]_{0} /} \\
{[\mathrm{Li}-i \mathrm{PrIB}]_{0}}\end{array}$ & Solvent & $T^{\mathrm{b}}$ & Equiv ${ }^{c}$ & $\begin{array}{c}\text { Temp./ } \\
{ }^{\circ} \mathrm{C}\end{array}$ & $\begin{array}{c}\text { Time/ } \\
\mathrm{h}\end{array}$ & & & & $\mathrm{mm}$ & $m r$ & $r r$ & $F^{f} / \%$ \\
\hline 7 & $20 / 1$ & $\mathrm{CH}_{2} \mathrm{Cl}_{2}$ & $\mathrm{H}_{3} \mathrm{O}^{+}$ & excess & -78 & $>0$ & st-1 & 2800 & 1.06 & $\sim 0$ & 13 & 87 & - \\
\hline 8 & $20 / 1$ & $\mathrm{CH}_{2} \mathrm{Cl}_{2}$ & 1a & 5.0 & -78 & 1 & st-2 & 3200 & 1.06 & & & & 98 \\
\hline 9 & $20 / 1$ & $\mathrm{CH}_{2} \mathrm{Cl}_{2}$ & $1 \mathrm{a}$ & 5.0 & -78 & 5 & st-3 & 2600 & 1.06 & & & & 99 \\
\hline 10 & $20 / 1$ & $\mathrm{CH}_{2} \mathrm{Cl}_{2}$ & $1 \mathbf{a}$ & 5.0 & -40 & 1 & st-4 & 3300 & 1.06 & & & & 91 \\
\hline 11 & $100 / 1$ & $\mathrm{CH}_{2} \mathrm{Cl}_{2}$ & $1 \mathbf{a}$ & 5.0 & -78 & 1 & st-5 & 11300 & 1.08 & $\sim 0$ & 11 & 89 & 100 \\
\hline 12 & $200 / 1$ & $\mathrm{CH}_{2} \mathrm{Cl}_{2}$ & $1 \mathrm{a}$ & 5.0 & -78 & 1 & st-6 & 23700 & 1.07 & $\sim 0$ & 9 & 91 & 99 \\
\hline 13 & $20 / 1$ & $\mathrm{CH}_{2} \mathrm{Cl}_{2}$ & $1 \mathrm{a}$ & 0.50 & -78 & 1 & st-7 & 3200 & 1.06 & & & & 80 \\
\hline 14 & $20 / 1$ & $\mathrm{CH}_{2} \mathrm{Cl}_{2}$ & 1a & 3.0 & -78 & 1 & st-8 & 3100 & 1.06 & & & & 100 \\
\hline 15 & $20 / 1$ & $\mathrm{CH}_{2} \mathrm{Cl}_{2}$ & $1 b$ & 5.0 & -78 & 1 & st-9 & 3000 & 1.08 & & & & 99 \\
\hline 16 & $20 / 1$ & Toluene & $1 b$ & 5.0 & -78 & 1 & st-10 & 2100 & 1.12 & & & & 95 \\
\hline 17 & $20 / 1$ & Toluene & $1 b$ & 5.0 & $-78 \rightarrow 0^{\mathrm{g}}$ & 1 & st-11 & 2100 & 1.14 & & & & 98 \\
\hline
\end{tabular}

${ }^{a}$ Polymerizations of MMA (5.0 mmol) were carried out in solvent $(5.0 \mathrm{~mL})$ at $-78{ }^{\circ} \mathrm{C}$ for $24 \mathrm{~h} .{ }^{b}$ Terminating agent. ${ }^{c}$ Equivalent of terminating agent to Li$i$ PrIB. ${ }^{d}$ Determined by SEC (PMMA standards). ${ }^{e}$ Estimated by ${ }^{1} \mathrm{H}$ NMR spectra. ${ }^{f}$ End-functionalization efficiency. ${ }^{g}$ Terminating agent was added at $-78{ }^{\circ} \mathrm{C}$ and then the reaction system was warmed to $0{ }^{\circ} \mathrm{C}$.

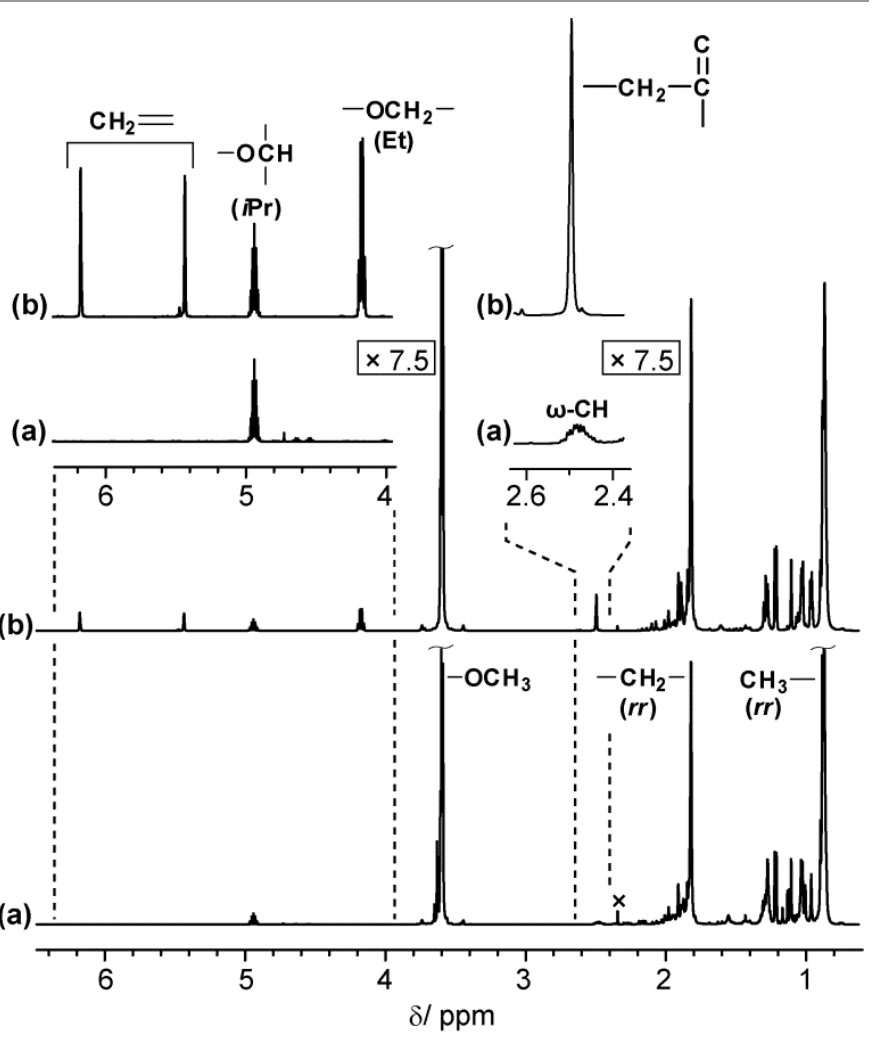

Fig. 2. ${ }^{1} \mathrm{H}$ NMR spectra of (a) st-1 and (b) st-2 $\left(500 \mathrm{MHz}^{\mathrm{C}} \mathrm{CDCl}_{3}, 55^{\circ} \mathrm{C}\right) . \times$ : toluene.

$\alpha-\mathrm{CH}_{3}$ signals were high $(r r$ content $=87 \%)$. As in the case of it -PMMA, the ${ }^{1} \mathrm{H}$ NMR spectrum of st-1 (Fig. 2a) exhibits the $\omega$-CH signal (2.48 ppm), while that of st-2 (Fig. 2b) showed the vinylidene (6.17 and $5.48 \mathrm{ppm}), O$-methylene $(4.17 \mathrm{ppm})$, and allylic protons $(2.52 \mathrm{ppm})$, indicating the smooth terminating reaction of $s t$-PMMA with 1a $(F=98 \%)$. Bulky aluminum bisphenoxides like EtAl(ODBP) 2 are known to form complexes with lithium ester enolate. ${ }^{41}$ In this polymerization system, therefore, the living enolate anion may strongly interact with $\mathrm{EtAl}(\mathrm{ODBP})_{2}$ to be stabilized so as to afford livingness (Scheme 1b). ${ }^{52}$ Although this ate-complex type propagating species have lower reactivity than free enolate anion, almost quantitative end-functionalization was achieved by the termination with 1a $(F=98 \%)$.

The terminating reaction seemed to complete within $1 \mathrm{~h}$ (Run 8: $F=98 \%$ ), and the $F$ value slightly increased after $5 \mathrm{~h}$ (Run 9: $F=99 \%$ ). The termination at $-40{ }^{\circ} \mathrm{C}$ resulted in lower $F$ value (Run 10: $F=91 \%$ ), although the reason was not clear. On the other hand, molecular weight did not affect the endfunctionalization (Runs 11, 12). Although the polymerization in toluene became highly viscous even when the $M_{\mathrm{n}}$ of the obtained PMMA was 2100, the termination with 1 b (Runs 16, 17) gave similar results to that in $\mathrm{CH}_{2} \mathrm{Cl}_{2}$ (Run 15).

The effect of amounts of added 1a was also investigated (Runs $8,13,14)$. It was found that the addition of 1.0 equiv. of 1a to initiator ( $\mathrm{Li}-i \mathrm{PrIB}$ ) was enough to terminate the polymerization quantitatively (Run 14). It should be noted that the initiator efficiency was $\sim 67 \%$ in this polymerization so that 1.0 equiv. of $1 \mathrm{a}$ was excess to the living anions. In fact, the addition of 0.50 equiv. of $1 \mathrm{a}$ resulted in $F=80 \%$ as the case of Run 13 . When the $F$ value is significantly lower than unity, the living PMMA remained might attack the $\omega$-end $\mathrm{C}=\mathrm{C}$ bond of the terminated PMMA to form higher molecular weight product (Scheme 2). The SEC trace of st-7 was unimodal distribution with a molecular weight dispersity $\left(M_{\mathrm{w}} / M_{\mathrm{n}}=1.06\right)$ as small as the other Runs. Thus, such a reaction did not occur, probably due to the bulkiness of PMMA chain attached to the $\mathrm{C}=\mathrm{C}$ bond, since the bulkiness of $\alpha$-substituent in $\alpha$-substituted acrylate drastically decreases the reactivity of vinylidene group.

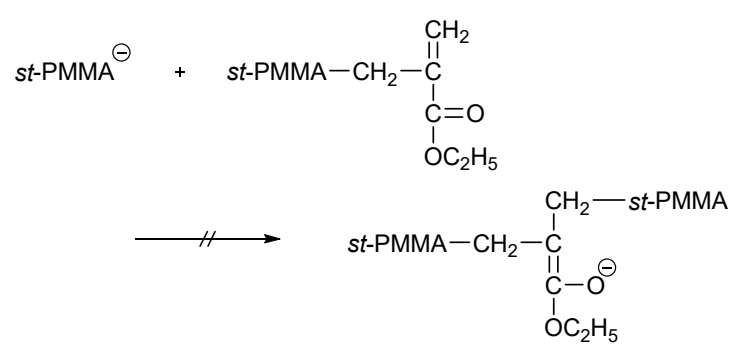

Scheme 2. Chain-transfer reaction to the generated $C-C$ bond at $\omega$-end. 
Table 3. Terminating reaction with 1a in stereospecific polymerization of various (meth)acrylates initiated by Li- $i \operatorname{PrIB} .{ }^{a}$

\begin{tabular}{|c|c|c|c|c|c|c|c|c|c|c|c|c|c|c|}
\hline \multirow{3}{*}{ Run } & \multicolumn{2}{|c|}{ Polymerization } & & & & \multicolumn{2}{|l|}{ Termination } & \multirow{3}{*}{ Polymer } & \multirow[b]{3}{*}{$M_{\mathrm{n}}^{c}$} & \multirow[b]{3}{*}{$M_{\mathrm{w}} / M_{\mathrm{n}}{ }^{c}$} & \multirow{2}{*}{\multicolumn{3}{|c|}{ Tacticity $1 \%^{d}$}} & \multirow[b]{3}{*}{$F^{d, e} / \%$} \\
\hline & \multirow{2}{*}{ Monomer (equiv.) ${ }^{b}$} & \multirow{2}{*}{ Additive (equiv.) ${ }^{b}$} & \multirow[b]{2}{*}{ Solvent } & \multirow{2}{*}{$\begin{array}{l}\text { Temp. } \\
/{ }^{\circ} \mathrm{C}\end{array}$} & \multirow{2}{*}{$\begin{array}{l}\text { Time } \\
\text { /h }\end{array}$} & \multirow{2}{*}{$\begin{array}{l}\text { Temp. } \\
/{ }^{\circ} \mathrm{C}\end{array}$} & \multirow{2}{*}{$\begin{array}{l}\text { Time } \\
/ \mathrm{h}\end{array}$} & & & & & & & \\
\hline & & & & & & & & & & & $m m$ & $m r$ & $r r$ & \\
\hline 18 & VMA (20) & $\mathrm{Me}_{3} \mathrm{SiOLi} \mathrm{(10)}$ & Toluene & -78 & 1 & -78 & 1 & V1 & 7400 & 1.08 & 98 & 2 & $\sim 0$ & 98 \\
\hline 19 & VMA (20) & $\mathrm{EtAl}(\mathrm{ODBP})_{2}(3.0)$ & Toluene & -78 & 24 & $-78 \rightarrow-30^{f e}$ & 1 & V2 & 4700 & 1.05 & $\sim 0$ & 13 & 87 & 98 \\
\hline 20 & TMSMA (50) & $\mathrm{Me}_{3} \mathrm{SiOLi}(10)$ & $\mathrm{CH}_{2} \mathrm{Cl}_{2}$ & -78 & 1 & -78 & 1 & TMS1 & 14000 & 1.46 & 94 & 4 & 2 & 94 \\
\hline 21 & TMSMA (50) & $\mathrm{MeAl}(\mathrm{ODBP})_{2}(3.0)$ & $\mathrm{CH}_{2} \mathrm{Cl}_{2}$ & -78 & 24 & $-78 \rightarrow 0^{f}$ & 24 & TMS2 & 2500 & 1.09 & 1 & 3 & 96 & 96 \\
\hline 22 & $\mathrm{BA}(50)$ & $\mathrm{EtAl}(\mathrm{ODBP})_{2}(5.0)$ & Toluene & -60 & 0.5 & -60 & 1 & B1 & 10800 & 1.16 & & & & 69 \\
\hline
\end{tabular}

${ }^{a}$ Solvent $=5.0 \mathrm{~mL}$, monomer $=5.0 \mathrm{mmol},[\mathrm{Li}-i \mathrm{PrIB}]_{0} /[\mathbf{1 a}]_{0}=1 / 5 .{ }^{b}$ Equivalent against Li-iPrIB ${ }^{c}$ Determined by SEC $(\mathrm{THF}$, PMMA standards $) .{ }^{d}$ Estimated by ${ }^{1} \mathrm{H}$ NMR spectroscopy $\left(500 \mathrm{MHz}, \mathrm{CDCl}_{3}, 55^{\circ} \mathrm{C}\right) .{ }^{e}$ End-functionalization efficiency. ${ }^{f}$ The reaction mixture was warmed to $-30{ }^{\circ} \mathrm{C} / 0{ }^{\circ} \mathrm{C}$ then stirred for $1 \mathrm{~h} / 24 \mathrm{~h}$.

\section{Terminating reaction with other (meth)acrylates}

The terminating reaction with $\mathbf{1 a}$ was applied to other (meth)acrylate monomers in order to reveal the applicable scope (Table 3). Although the stereospecific anionic polymerizations of sec-alkyl methacrylates such as isopropyl methacrylate are known not to be controllable well, we recently have found that of VMA can be controlled. ${ }^{42}$ Both in isotactic(Run 18) and syndiotactic- (Run 19) specific polymerizations of VMA, the terminating efficiencies with $1 a$ were almost quantitative $(F=98 \%)$. Although the stereospecific polymerizations of tert-alkyl esters, i.e. tert-butyl methacrylates, in the above mentioned conditions are not controllable, those of TMSMA have been established. ${ }^{43}$ Isotactic- and syndiotacticspecific polymerization of TMSMA was terminated with high efficiencies (Runs 21,22 ). Since the polymerization was finally quenched with $\mathrm{HCl}$ aq, the products were obtained as poly(methacrylic acid) due to the acid-hydrolysis of silyl ester.

As reported, polymerization of $\mathrm{BA}$ in the presence of EtAl(ODBP) 2 proceeds in a living manner. ${ }^{49}$ Thus, the termination with 1a was also applied to this polymerization system (Run 22). However, the terminating efficiency was not quantitative $(F=69 \%)$. This might be due to the low reactivity of the living polyacrylate anion (secondary carbanion) than that of polymethacrylate anion (tertiary carbanion), and further optimization of the conditions for the terminating reaction is under examination.

\section{Stereoregular PMMA and poly(methacrylic acid) with $\omega$ - functions via post-polymerization modification}

As the $\mathrm{C}=\mathrm{C}$ double bond at the $\omega$-end is activated by the carbonyl group, it can undergo Michael-addition type thiol-ene click chemistry. In fact, we previously reported the further functionalizations of the end-functional stereoregular PMMAs with various thiols (2a-d) (Scheme 3). In a similar way, endfunctionalization was attempted for other thiols and polymers.

Sugiyama et al. have reported that the chain-end modification of polymethacrylates with a perfluoroalkyl group mproves their water-repellency. ${ }^{45}$ Thus, thiol possessing perfluoroalkyl group, 2e, was reacted with st-PMMA in ethyl acetate at $50{ }^{\circ} \mathrm{C}$. Although the reaction mixture became heterogeneous, the conversion of terminal vinylidene group reached $92 \%$ after $48 \mathrm{~h}$. The reaction was then repeated again, and the conversion finally increased to $95 \%$. Bifunctional thiol

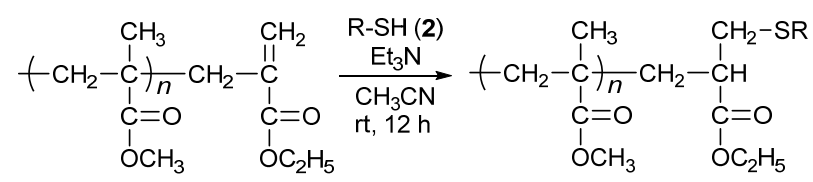

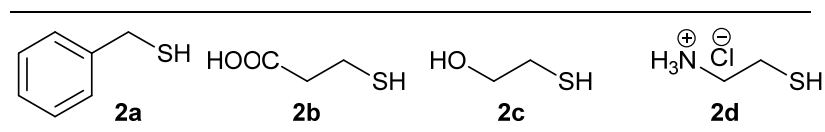<smiles>FC(F)(F)C(F)(F)C(F)(F)C(F)(F)C(F)(F)C(F)(F)CCS</smiles>

$2 e$

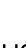

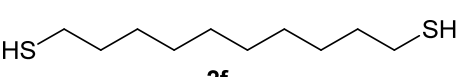

Scheme 3. End-functionalization by thiol-ene 'click' chemistry.

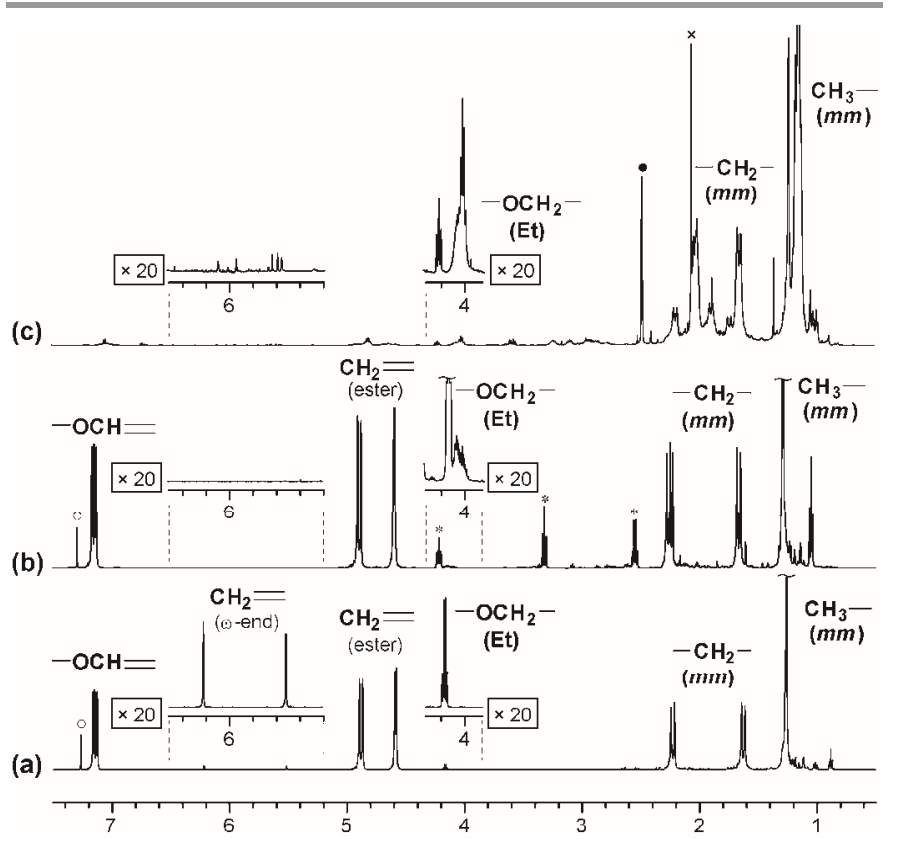

Fig. 3. ${ }^{1} \mathrm{H}$ NMR spectra of $\mathbf{V} \mathbf{1}(\mathrm{a})$ before and (b) after thiol-ene reaction with $\mathbf{2 d}$ in $\mathrm{CDCl}_{3}$, and (c) the hydrolysis product [poly(methacrylic acid)] in DMSO- $d_{6}$ (500 $\mathrm{MHz}, 55^{\circ} \mathrm{C}$ ). $\circ: \mathrm{CHCl}_{3}, \bullet$ : DMSO, $*$ : residual $\mathbf{2 d}, \times$ : acetone.

(2f) was also reacted to the terminal vinylidene group in order to incorporate thiol group at the $\omega$-end. To suppress the dimerization, a large excess (50-fold) of $\mathbf{2 f}$ was reacted with stPMMA (st-4). Since the SEC profile of the obtained polymer agreed with its precursor, no dimerization occurred under this 


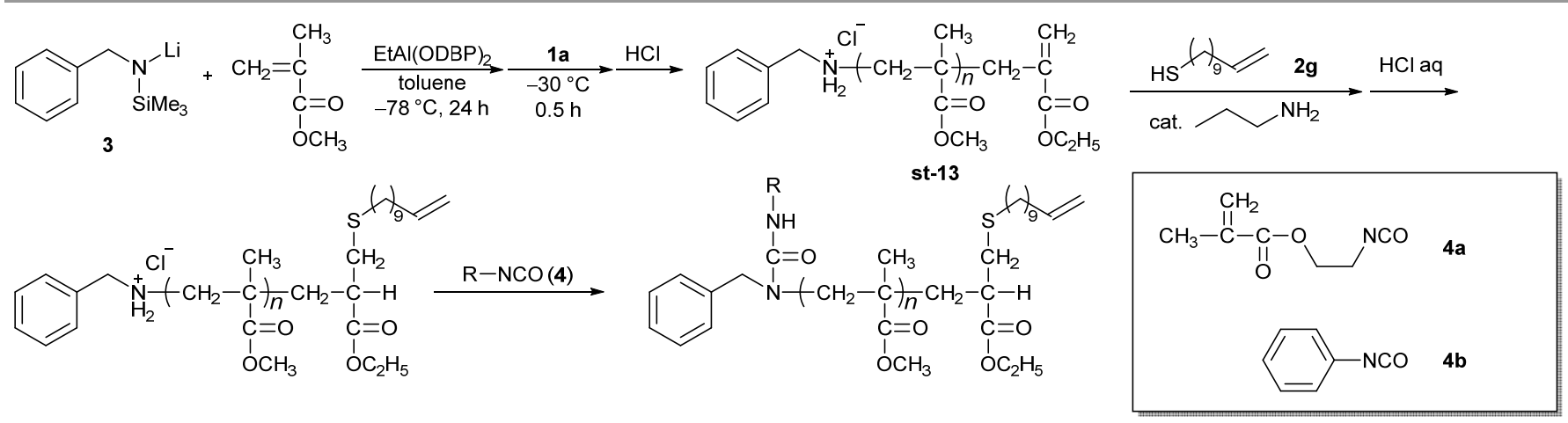

Scheme 4. Synthesis and double click reaction of hetero-telechelic st-PMMA.

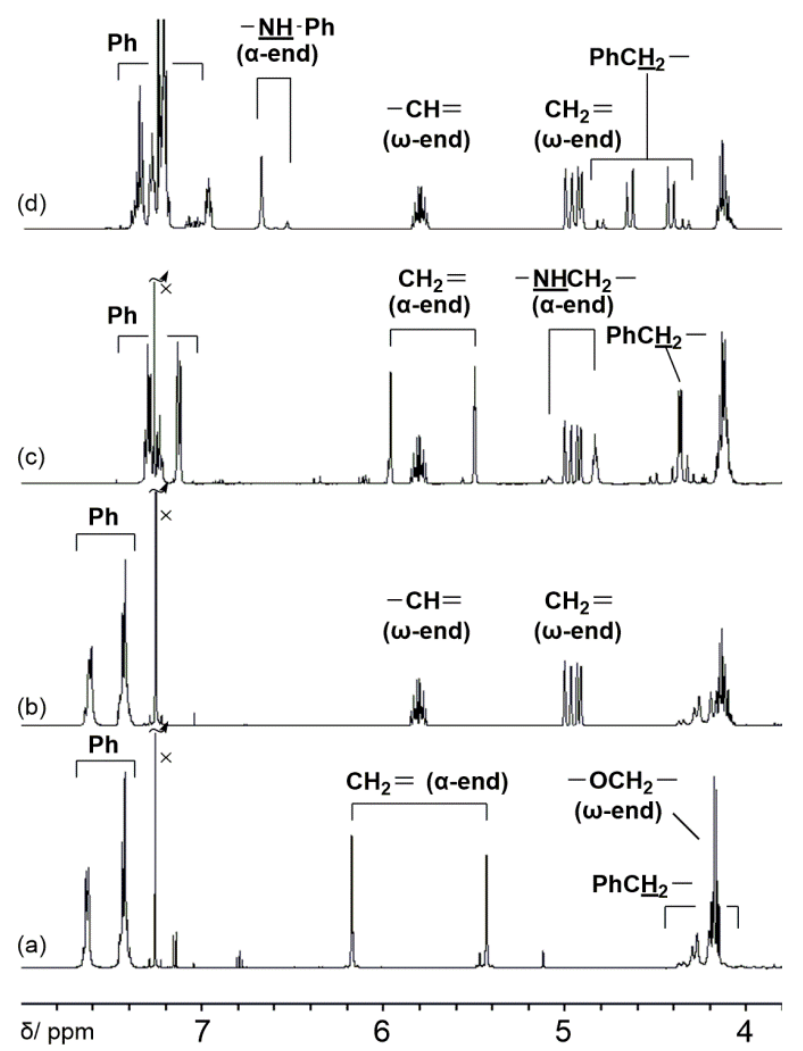

Fig. 4. ${ }^{1} \mathrm{H}$ NMR spectra of st14 (a) before and (b) after thiol-ene reaction with $\mathbf{2 g}$, and (c) the product after amine-isocyanate reaction with $\mathbf{4 a}$ and that with $\mathbf{4 b}$ $\left(500 \mathrm{MHz}, \mathrm{CDCl}_{3}, 55^{\circ} \mathrm{C}\right) \cdot \times: \mathrm{CHCl}_{3}$.

condition.

The effect of molecular weight on the thiol-ene 'click' reactions was also investigated with it-4 $\left(M_{\mathrm{n}}=28000\right)$, st-5 $\left(M_{\mathrm{n}}\right.$ $=11300)$, and st-6 $\left(M_{\mathrm{n}}=23700\right)$. Due to the higher molecular weight of these polymers, the concentration of the functional group was set to be $20 \mathrm{mM}$ instead of $100 \mathrm{mM}$ in the previous cases, where the reaction mixtures were even more viscous. Nevertheless, quantitative end-functionalization was achieved without any further experimental modification such as reaction period and temperature.
In the case of poly(VMA), the vinylidene group at the $\omega$-end is activated by the carbonyl group enough to allow the Michaeladdition of thiol, while the vinyl ester groups in the monomeric units are inactive against the Michel-addition. Thus, the orthogonal and stepwise modifications of the vinylidene and vinyl groups are possible. Treatment of it-poly(VMA) (V1) with $2 d$ in the presence of $\mathrm{Et}_{3} \mathrm{~N}$ afforded an aminefunctionalized polymer. In ${ }^{1} \mathrm{H}$ NMR spectra (Fig. 3), the vinylidene signals $(6.22$ and $5.52 \mathrm{ppm})$ completely disappeared, while the vinyl ester signals $(7.15,4.88$, and $4.59 \mathrm{ppm})$ did not change. Then the end-functionalized polymer was hydrolyzed with $\mathrm{CF}_{3} \mathrm{COOH}$. The obtained polymer did not show the vinyl signals. Consequently, the synthesis of end-functional stereoregular poly(methacrylic acid) was achieved.

\section{Stereoregular PMMA with orthogonally-clickable $\alpha$ - and $\omega$-ends}

Recently, polymer architectures by orthogonal double click reactions at both ends have gained much attention. ${ }^{46} \mathrm{We}$ have previously reported that a silyl-protected lithium amide initiator (3) in combination with aluminum compounds was effective for syndiotactic-specific polymerization of MMA, which allows the incorporation of a secondary amino group at the $\alpha$-end of PMMA. ${ }^{37}$ As well known, a secondary amino group can be applied to click chemistry through urea-formation with an isocyanate. Hence, a combination of $\mathbf{3}$ as a functional initiator and 1a as an efficient terminating agent may afford heterotelechelic st-PMMA with orthogonally-clickable ends (Scheme 4). In fact, the anionic polymerization gave st-PMMA (st-13: $\left.M_{\mathrm{n}}=3200, M_{\mathrm{w}} / M_{\mathrm{n}}=1.06, m m / m r / r r=0 / 13 / 87, F=98 \%\right)$.

11-Mercaptoundec-1-ene (2g) was prepared in situ from the corresponding thioester with propylamine and reacted with st13. Fig. 4 shows the ${ }^{1} \mathrm{H}$ NMR spectral changes after the reaction. Apparently, the signals of vinylidene protons due to the $\omega$-end group disappeared and those of vinyl protons derived from $\mathbf{2 g}$ were observed, indicating the complete thiol-ene click reaction. Subsequently, the product was reacted with 2isocyanatoethyl methacrylate $(\mathbf{4 a})$. Fig. $4 \mathrm{c}$ shows the shift of signals assignable to aromatic protons and the appearance of new signals assignable to the vinylidene protons (5.50 and 5.97 $\mathrm{ppm})$ and that of the urea proton $(4.27-4.57 \mathrm{ppm})$. These 

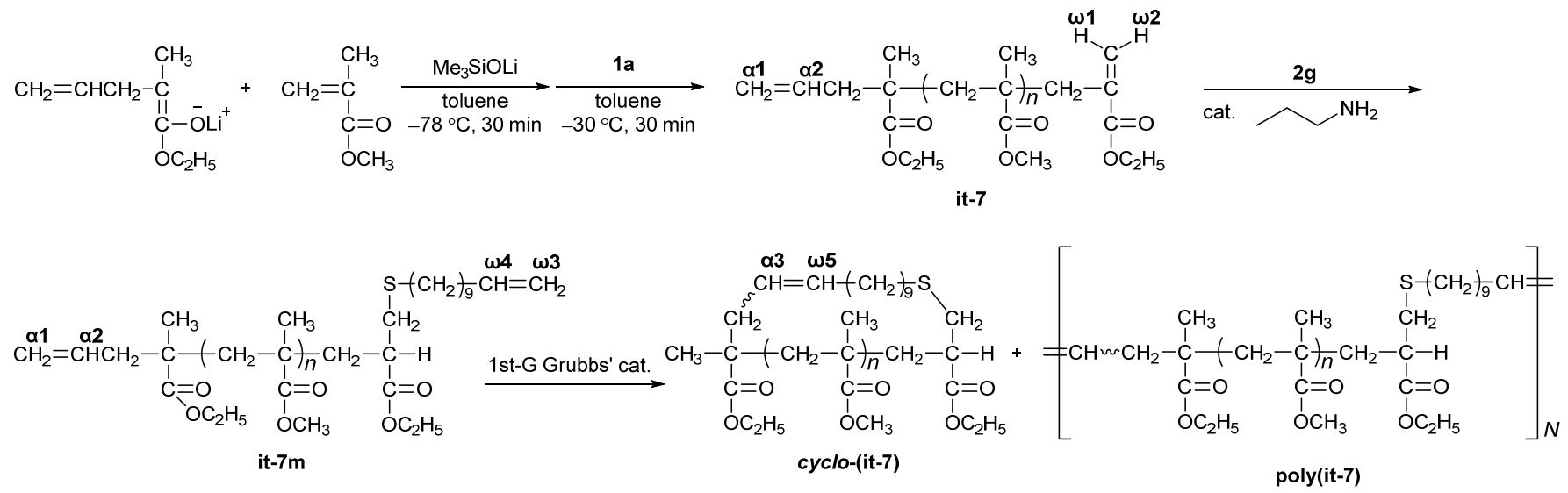

Scheme 5. Synthesis and olefin-metathesis reaction of telechelic it-PMMA.

spectral changes indicated that the second click reactions proceeded completely without any side reactions. Furthermore, one-pot double-click reactions were investigated by using phenyl isocyanate (4b) in place of $4 a$ to avoid a side reaction of the unreacted thiol to $\mathbf{4 a}$. After the first click reaction with $\mathbf{2 g}$, an excess amount of $\mathbf{4 b}$ was added. ${ }^{1} \mathrm{H}$ NMR spectral changes similar to the stepwise click reactions were observed (Fig. 4d), and thus it is concluded that quantitative double endfunctionalization was achieved via orthogonal double click reactions.

\section{Attempted synthesis of cyclic polymer}

Recently, Kamigaito et al. have reported that cyclic (cyclo-)stPMMA forms polypseudorotaxane with it-PMMA. ${ }^{47}$ Inspired by this work, we have attempted the synthesis of cyclo-itPMMA from a telechelic PMMA with vinyl groups at the both ends by olefin-metathesis reaction. ${ }^{48,49}$ The telechelic it-PMMA (it-7m) was prepared through two step reactions; an isotacticspecific polymerization of MMA was initiated by a lithium enolate of ethyl 2-methylpent-4-enoate and terminated with 1a to afford it-7 $\left(M_{\mathrm{n}}=5100, M_{\mathrm{w}} / M_{\mathrm{n}}=1.24, F=96 \%, \mathrm{~mm} / \mathrm{mr} / \mathrm{rr}\right.$ $=96 / 4 / 0$ ), followed by the thiol-ene reaction with $\mathbf{2 g}$ (Scheme 5). The obtained telechelic polymer, it-7m, was refluxed with the first generation Grubbs' catalyst in $\mathrm{CH}_{2} \mathrm{Cl}_{2}$ $\left(1.0 \times 10^{-4} \mathrm{M}\right)$ for 4 days. In ${ }^{1} \mathrm{H}$ NMR spectra (Fig. 5), the vinylidene signals ( $\omega 1$ : $6.16 \mathrm{ppm}, \boldsymbol{\omega 2} 2: 5.48 \mathrm{ppm}$ ) disappeared and after the thiol-ene reaction, and new vinyl proton signals

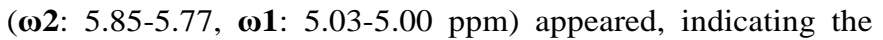
quantitative end-functionalization. These end-group signals disappeared almost completely after the olefin-metathesis reaction, while new olefinic proton signals ( $\alpha 3 / \omega 5$ : 5.82-5.71 and 5.14-5.07 ppm) assignable to the generated vinylene group appeared, indicating the high efficiency of metathesis reaction. However, the increase in molecular weight (peak top: $M_{\mathrm{p}}=$ $67000)$ from the precursor $\left(M_{\mathrm{p}}=7700\right)$ was observed in the SEC trace of the product, although a small second peak at lower molecular weight $\left(M_{\mathrm{p}}=6700\right)$ was also seen (Fig. 6). The former peak indicates the polycondensation of it-7, and the resulting polymer [poly-(it-7)] was estimated as $c a$. 9 mer of it-
7 in average from the increase in $M_{\mathrm{p}}$. The latter peak is presumably a targeted cyclic polymer, [cyclo-(it-7)], since the

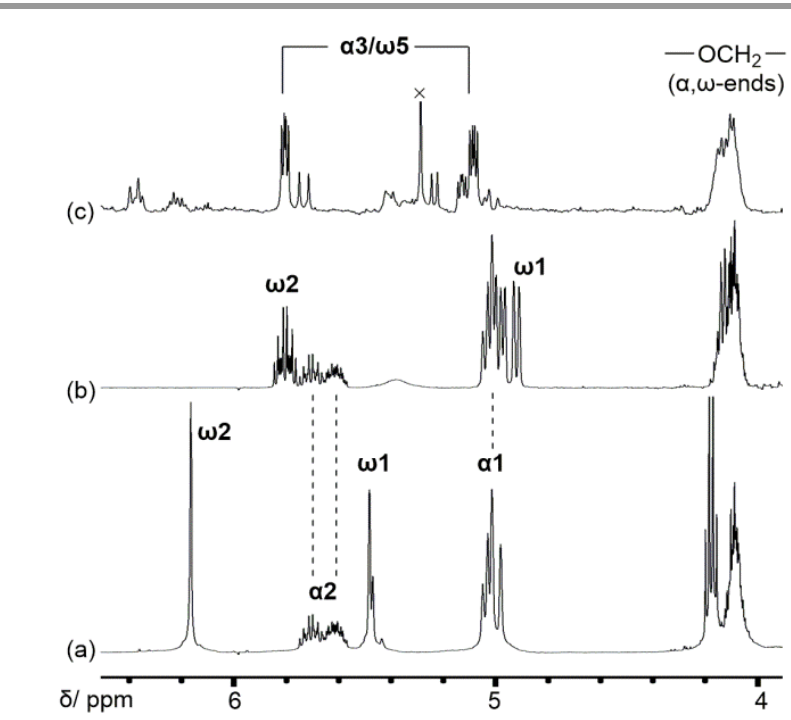

Fig. 5. ${ }^{1} \mathrm{H}$ NMR spectra of it-7 (a) before and (b) after thiol-ene reaction with $\mathbf{2 g}$, and (c) after olefin-metathesis reaction $\left(500 \mathrm{MHz}, \mathrm{CDCl}_{3}, 55^{\circ} \mathrm{C}\right) . \times: \mathrm{CH}_{2} \mathrm{Cl}_{2}$. For notations of end-groups, refer to Scheme 5.

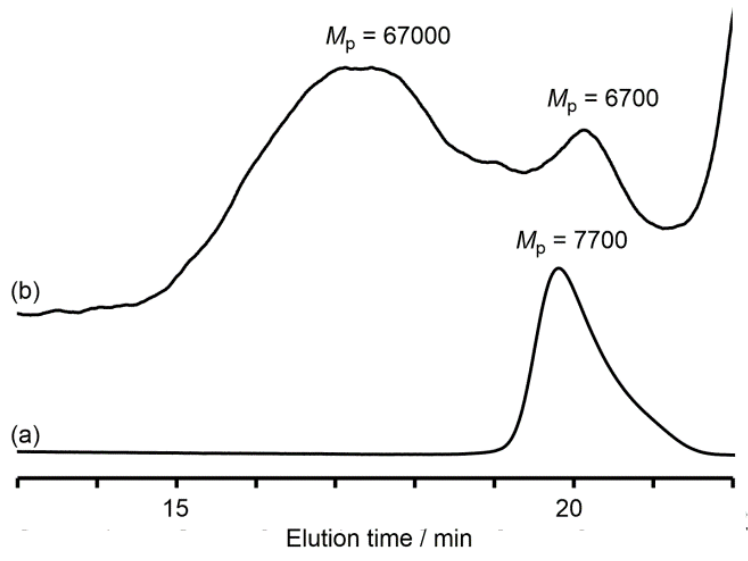

Fig. 6. SEC traces of it-7m (a) before and (b) after olefin-metathesis. 
$M_{\mathrm{p}}$ was 0.87 times of the precursor as expected from smaller hydrodynamic volume of a cyclic polymer than the respective linear polymer. ${ }^{49,50}$

\section{Conclusions}

Stereoregular $\omega$-functional PMMAs were synthesized by the combination of terminating reactions of stereospecific living anionic polymerizations and click chemistry. $\alpha$-(Halomethyl)acrylates were highly active in terminating reaction of PMMA living anion so that almost quantitative end-functionalization was achieved. The terminating reaction was found to proceed with high efficiency in the polymerization of VMA and TMSMA. The incorporated $\mathrm{C}=\mathrm{C}$ double bond underwent Michael addition of functional thiols to allow further endfunctionalizations. This reaction was also possible for poly(VMA), which afforded the $\omega$-functional poly(methacrylic acid) after hydrolysis. The combination of functional initiator and the terminating agent resulted in hetero-telechelic PMMAs, which allowed orthogonal double-click reactions at the both ends.

One of the goals of precise polymerization chemistry is simultaneous control of primary structures of macromolecules such as molecular weight, configuration and end-functionality. The above results are the successful example of them with highly sophisticated level in the polymerization of methacrylates. Nowadays, the growth of needs for endclickable polymer has drastically increased not only in polymer chemistry but also in the fields of material science and medical science, as the concept of 'click chemistry' has become a robust, facile, and efficient methodology for chemical ligation in those areas. The current results may be a bridge builder between two concepts, stereospecific anionic polymerization and endclickable polymer, and promote the use of a stereoregular polymers as building blocks at an edge of polymer science.

\section{Acknowledgements}

This work was financially supported by KAKENHI (No. 24750108) from MEXT, Japan. We appreciate Showa Denko K.K. for a kind gift of 2-isocyanatethyl methacrylate. We also appreciate Nippon Shokubai Co. Ltd. for a kind gift of ethyl $\alpha$ (hydroxymethyl)acrylate. $\quad 3,3,4,4,5,5,6,6,7,7,8,8,8$-Tridecafluorooctane-1-thiol was a kind gift from Daikin Industries, Ltd.

\section{Notes and references}

${ }^{a}$ Department of Chemistry, Graduate School of Engineering Science, Osaka University, 1-3 Machikaneyama, Toyonaka, Osaka 560-8531, Japan. e-mail: kitayama@chem.es.osaka-u.ac.jp Tel: +81-6-6850-6230 Fax: +81-6-6841-0104

1 M. Tasdelen, M. Kahveci and Y. Yagci, Prog. Polym. Sci., 2011, 36 455 .

2 J. Opsteen and J. van Hest, Chem. Commun., 2005, 57.

3 T. Nishiura, Y. Abe and T. Kitayama, Polym. J., 2010, 42, 868.
4 Y. Kohsaka, Y. Koyama and T. Takata, Angew. Chem., Int. Ed., 2011, 50, 10417.

5 A. Hirao, K. Murano, T. Oie, M. Uematsu, R. Goseki and Y. Matsuo, Polym. Chem., 2011, 2, 1219.

6 P. J. Roth, D. Kessler, R. Zentel and P. Theato, J. Polym. Sci., Part A: Polym. Chem., 2009, 47, 3118.

7 W. Yang, K. Neoh, E. Kang, S. Teo and D. Rittschof, Polym. Chem., 2013, 4, 3105.

8 G. Chen, L. Tao, G. Mantovani, V. Ladmiral, D. Burt, J. Macpherson and D. M. Haddleton, Soft Matter, 2007, 3, 732.

9 L. Tao, C. S. Kaddis, R. R. O. Loo, G. N. Grover, J. A. Loo and H. D. Maynard, Macromolecules, 2009, 42, 8028.

10 G. Grover, S. Alconcel, N. Matsumoto and H. Maynard, Macromolecules, 2009, 42, 7657.

11 R. Iha, K. Wooley, A. Nystrom, D. Burke, M. Kade and C. Hawker, Chem. Rev., 2009, 109, 5620.

12 A. Lowe, Polym. Chem., 2010, 1, 17.

13 M. Kade, D. Burke and C. Hawker, J. Polym. Sc., Part A: Polym. Chem., 2010, 48, 743.

14 B. Yu, J. W. Chan, C. E. Hoyle and A. B. Lowe, J. Polym. Sc., Part A: Polym. Chem., 2009, 47, 3544.

15 D. Quémener, T. P. Davis, C. Barner-Kowollik and M. H. Stenzel, Chem. Commun., 2006, 5051.

16 G. Gody, C. Rossner, J. Moraes, P. Vana, T. Maschmeyer and S. Perrier, J. Am. Chem. Soc., 2012, 134, 12596.

17 V. Coessens, Y. Nakagawa and K. Matyjaszewski, Polym. Bull., 1998, 40, 135.

18 V. Coessens and K. Matyjaszewski, J. Macromol. Sci. Pur. Appl. Chem., 1999, A36, 667.

19 J. Geng, J. Lindqvist, G. Mantovani and D. M. Haddleton, Angew. Chem. Int. Ed., 2008, 47, 4180.

20 A. Inglis, T. Paulohrl and C. Barner-Kowollik, Macromolecules, $2010, \mathbf{4 3}, 33$.

21 M. Liras, O. Garcia, I. Quijada-Garrido and R. Paris, Macromolecules, 2011, 44, 1335.

22 I. Gadwal and A. Khan, Polym. Chem., 2013, 4, 2440.

23 A. Dag, H. Durmaz, G. Hizal and U. Tunca, J. Polym. Sc., Part A: Polym. Chem., 2008, 46, 302.

24 K. Satoh and M. Kamigaito, Chem. Rev., 2009, 109, 5120.

25 K. Ute, N. Miyatake, T. Asada and K. Hatada, Polym. Bull., 1992, 28, 561.

26 T. Nakano, A. Matsuda and Y. Okamoto, Polym. J., 1996, 28, 556.

27 Y. Okamoto, T. Nakano, Y. Shikisai and M. Mori, Macromol. Symp., $1995,89,479$

28 T. Nakano, M. Mori and Y. Okamoto, Macromolecules, 1993, 26, 867.

29 Y. Isobe, K. Yamada, T. Nakano and Y. Okamoto, J. Polym. Sc., Part A: Polym. Chem.,, 2000, 38, 4693.

30 Y. Isobe, K. Yamada, T. Nakano and Y. Okamoto, Macromolecules, 1999, 32, 5979 .

31 Y. Miura, T. Satoh, A. Narumi, O. Nishizawa, Y. Okamoto and T. Kakuchi, J. Polym. Sc., Part A: Polym. Chem., 2006, 44, 1436.

32 T. Kitaura and T. Kitayama, Macromol. Rapid Commun., 2007, 28, 1889.

33 T. Kitayama, T. Shinozaki, T. Sakamoto, M. Yamamoto and K. Hatada, Makromol. Chem., Suppl., 1989, 15, 167. 
34 E. T. B. Altakrity, A. D. Jenkins and D. R. M. Walton, Makromol. Chem. Macromol. Chem. Phys., 1990, 191, 3073.

35 E. T. B. Altakrity, A. D. Jenkins and D. R. M. Walton, Makromol. Chem. Macromol. Chem. Phys., 1990, 191, 3069.

36 T. Kitayama, O. Nakagawa, S. Kishiro, T. Nishiura and K. Hatada, Polym. J. , 1993, 25, 707.

37 T. Kitaura and T. Kitayama, Polym. J., 2008, 40, 37.

38 T. Kitaura and T. Kitayama, Polym. J., 2013, 45, 1013.

39 Y. Kohsaka, T. Kurata and T. Kitayama, Polym. Chem., 2013, 4, 5043

40 T. Kitayama, T. Hirano and K. Hatada, Tetrahedron, 1997, 53, 15263.

41 A. Rodriguez-Delgado and E. Y. X. Chen, J. Am. Chem. Soc., 2005, 127, 961.

42 T. Kitaura, T. Yoshioka, and T. Kitayama, to be published.

43 T. Kitayama, S. He, Y. Hironaka, T. Iijima and K. Hatada, Polym. J., 1995, 27, 314.

44 M. Tabuchi, T. Kawauchi, T. Kitayama and K. Hatada, Polymer, 2002, 43, 7185.

45 K. Sugiyama, A. Hirao and S. Nakahama, Macromol. Chem. Phys., 1996, 197, 3149.

46 H. Durmaz, A. Sanyal, G. Hizal and U. Tunca, Polym. Chem., 2012, 3, 825 .

47 J. M. Ren, K. Satoh, T. K. Goh1, A. Blencowe, K. Nagai, K. Ishitake, A. J. Christofferson, G. Yiapanis, I. Yarovsky, M. Kamigaito and G. G. Qiao, Angew.Chem. Int. Ed., 2014, 53, 459.

48 Y. Tezuka, Polym. J., 2012, 44, 1159.

49 S. Hiyashi, K. Adachi and Y. Tezuka, Chem. Lett., 2007, 36, 982.

50 B. A. Laurent and S. M. Grayson, Chem. Soc. Rev., 2009, 38, 2202. 